\title{
АДМИНИСТРАТИВНО-ПРАВОВОЕ РЕГУЛИРОВАНИЕ ПРИМЕНЕНИЯ ГЕНОМНЬХ ТЕХНОЛОГИЙ В СЕЛЬСКОМ ХОЗЯЙСТВЕ ИСПАНИИ
}

Актуальность статьи обусловлена необходимостью совершенствования российского механизма административно-правового регулирования применения геномных технологий в сельском хозяйстве, сформированного фрагментарно и не позволяющего в нынешнем состоянии достигать целей регулирования - обеспечения безопасности человека и окружающей среды при работах с генетически-модифицированными организмами (далее ГМО). Предметом статьи является изучение опыта административно-правового регулирования использования и выращивания ГМО в Королевстве Испания, которая является крупной аграрной страной и одним из двух государств Европейского Союза, выращивающих ГМО на своей территории. Целью статьи является выделение норм, рецепция которых российским правом послужила бы построению сбалансированного механизма административно-правового регулирования применения геномных технологий в растениеводческом сельском хозяйстве. Методологическую основу исследования составляет применение сравнительно-правового и формально-юридического методов в совокупности с системно-логическим методом познания. В результате исследования было установлено, что целый ряд положений законодательства Испании о ГМО может быть воспринят российским правом, что позволит решить многие проблемы правового регулирования получения и выращивания ГМО в России. Это положения об оценке уровня риска при использовании ГМО, о мерах предосторожности, которые могут принимать государственные органы при обнаружении нарушений и угрозы защищаемым объектам, о мерах административной ответственности за нарушение требований к использованию и выращиванию ГМО, о создании межведомственных органов для обеспечения безопасности при использовании ГМО. Законодательство Испании детально проработано и основано на общеевропейских правилах регулирования, характеризующихся строгостью в отношении применения геномных технологий. В стране более 20 лет выращивается геномно-модифицированная кукуруза, в связи с чем нормы законодательства являются реально действующими в том, что касается выпуска ГМО в окружающую среду и реализации ГМО и позволяет применять в связи с чем может стать серьезной базой для формирования современного российского механизма административно-правового регулирования применения геномных технологий в российском растениеводстве.

Ключевые слова: ГМО, геномные технологии, растениеводство, административно-правовое регулирование, административная ответственность, законодательство Испании.

\section{A. Sokolov, N. Bogatyreva}

\section{LEGAL REGULATION OF GENOMIC TECHNOLOGIES APPLICATION} FOR AGRICULTURE OF SPAIN

The paper is relevant because of the need to improve the Russian mechanism of administrative and legal regulation of genomic technologies application for agriculture This mechanism is built fragmentary and in the current state does not allow achieving regulatory objectives, such as providing human and environmental safety when using genetically modified organisms (GMOs). The subject of the paper is the study of the experience of administrative and legal regulation of GMOs use and cultivation of in the Kingdom of Spain, which is a large agricultural country and one of two European Union countries that grow GMOs. The purpose of the paper is to highlight the norms, the reception of which by Russian law would serve to build a balanced mechanism of administrative and legal regulation of genomic technologies application for crop agriculture. The methodologica basis of the study based on using comparative legal and formal legal methods in line with the system-logical cognition method. Because of the study, it was found that a number of provisions of the Spanish legislation on GMOs can be accepted by Russian law. It will solve many prob- lems of the legal regulation of the production and cultivation of GMOs in Russia. These are risk level determination in the use of GMOs; precaution measures that state bodies may take when detecting violation and threats to protected objects; administrative responsibility measures for violation of requirements for the use and cultivation of GMOs; creation of interdepartmental bodies to ensure safety when using GMOs. Spanish legislation is elaborated in detail and is based on pan-European regulatory rules, characterized by rigor in the application of genomic technologies. More than 20 years, genome-modified maize has been grown in Spain, and therefore the legal norms are tested by practice of the release of GMO into the environment and the implementation of GMOs. Therefore, Spanish legislation can be used as a serious basis for the formation of a modern Russian administrative legal mechanism of genomic technologies application for Russian crop production.

Key words: GMOs, genomic technologies, crop production, administrative legal regulation, administrative responsibility, Spanish legislation.

${ }^{1}$ Исследование выполнено при финансовой поддержке РФФИ в рамках научного проекта № 18-29-14048. 
Административно-правовое регулирование выращивания в России генетически модифицированных организмов (далее - ГМО) основывается на признании присущего им риска и необходимости его минимизации и устранения. В последние годы в российском законодательстве реализуется наиболее строгая из возможных концепций регулирования в отношении ГМО - абсолютный запрет на их выращивание в хозяйственных целях, введенный в 2016 году. Этот подход создает угрозы для национальной экономической и продовольственной безопасности:

- во-первых, создаются условия для научного и технического отставания в области получения генетически модифицированных (далее - ГМ) сортов растений, имеющих хозяйственную, медицинскую ценность. Запрет на выращивание ГМО в России направлен на защиту отечественного рынка органической продукции, он имеет экономический и политический характер. В то же время все больше современных исследований свидетельствуют о безопасности употребления в пищу ГМО [10], а опубликованные ранее научные статьи переоцениваются [21], появляются новые, более безопасные технологии, в связи с чем стратегически неверно полностью отказываться от разработок в области ГМ-растениеводства.

О необходимости поддержки геномных технологий в растениеводстве говорится и в Комплексной программе развития биотехнологий в Российской Федерации на период до 2020 года, утвержденной Правительством РФ [2];

- во-вторых, Россия становится зависимой от импорта зарубежной продукции, полученной из ГМО, поскольку российские производители не могут произвести импортозамещающие аналоги в силу запрета;

- в-третьих, в России не развивается законодательство, регулирующее порядок использования ГМО в замкнутых системах - в лабораториях и на производстве. Законодательство содержит много пробелов, в частности, отсутствуют порядок оценки риска ГМО и требования к безопасности при работах с ГМО;

- в четвертых, несмотря на разрешение выращивать ГМО в научно-исследовательских и экспертных целях, требования оценки рисков такой деятельности отсутствуют, как и правила безопасного выращивания.

В сложившейся ситуации возможной моделью правового регулирования выращивания ГМО может стать заимствование опыта европейских стран. Опыт стран Европейского Союза (далее ЕС) может быть релевантен, во-первых, в силу географической близости данного региона к европейской части России, во-вторых, в силу повышенного внимания европейских регуляторов к защите традиционного органического земледелия и настороженного отношения к ГМО в сельском хозяйстве. Это в целом соответствует общественно-политическому контексту восприятия ГМО в России. В ЕС много стран, в которых выращивание ГМ-культур в настоящий момент запрещено, но имеется проработанное законодательство по вопросам безопасности работы с ГМО и выпуска их в окружающую среду.

Целью настоящей статьи является подготовка предложений по рецепции российским правом отдельных элементов механизма правового регулирования использования ГМО в Испании - как одной из немногих стран ЕC, в которых ведется хозяйственное выращивание ГМО. Это позволит в будущем разработать действенный механизм административно-правового регулирования применения геномных и постгеномных технологий в российском растениеводстве

Как отмечает Ю. А. Петушкова, система правового регулирования в области биотехнологии в Испании отражает высокую степень развития и государственную поддержку отрасли. Ее положительный опыт должен быть заимствован Российской Федерацией для совершенствования и восполнения пробелов в законодательстве, регулирующем отношения в области биотехнологии [6, c. 25].

Для целей исследования необходимо обобщить опыт правового регулирования выращивания ГМО в Испании и выделить нормы, которые могут быть полезны для российского механизма регулирования ГМО, помогут устранить имеющиеся проблемы и недостатки правового регулирования.

В первую очередь следует охарактеризовать правовой контекст такого регулирования - наднациональное законодательство ЕС по вопросам выращивания ГМО.

Законодательство стран ЕС - это наднациональное региональное право [8]. В компетенцию общеевропейского регулятора входят вопросы построения общего рынка, единого внутреннего рынка, проведения общей сельскохозяйственной и торговой политики, а также осуществления мер по охране окружающей среды на территории государств-членов ЕС. Регламентация правоотношений в указанных сферах подразумевает решение вопросов, связанных с получением и выращиванием ГМО.

Среди важнейших актов ЕС прямого действия, регулирующих такие отношения, следует назвать Директиву 2001/18/EC от 12 марта 2001 г. о преднамеренном выпуске в окружающую среду генетически модифицированных организмов [13].

В 2015 году Директива 2001/18/ЕС была существенно скорректирована Директивой 2015/412/ EC [14]. Члены EC получили право ограничивать или запрещать выращивание на своей территории ГМО, одобренных в ЕС, не по причине их опасности для человека или окружающей среды, а по социально-экономическим причинам, например, в соответствии с целями сельскохозяйственной политики.

Директива ЕС требует имплементации ее норм в национальное законодательство посредством принятия национального правового акта или их системы [9]. Таким образом, наличие общих рамок правового регулирования не исключает реа- 
лизации национального подхода в законодательстве определенных стран

Многие страны ЕС в соответствии с Директивой ЕС 2015/412/ЕС исключили свои территории из зоны для выращивания ГМ-растений, получивших разрешение на выращивание в EC, например, - Германия [5]

Однако есть и государства, которые не воспользовались такой возможностью и осуществляют коммерческое выращивание ГМО на своей территории, в рамках ЕС это Португалия и Испания. По данным за 2017 год, в Испании выращивалось более 91 \% всех европейских биотехнологических культур [16]

Использование ГМО в сельском хозяйстве Испании основывается на целом комплексе нормативных документов.

Закон № 45/2007 об устойчивом развитии сельской среды [20] направлен на защиту устойчивого развития сельской среды. В российском законодательстве нет аналогичного по назначению закона: он содержит целый комплекс мер по развитию сельского хозяйства, административного, экономического и социально-экономического характера.

В законе говорится о необходимости диверсифицировать сельское хозяйство, и одной из мер по диверсификации является продвижение новых видов деятельности с высокой добавленной стоимостью.

Как раз к таким видам деятельности относится получение продукции биотехнологического сельского хозяйства, поскольку генетическая модификация позволяет получать сорта с повышенной производительностью, а также уменьшать затраты на пестициды и инсектициды.

Так, в Испании выращивается единственная разрешенная в EC ГМ-кукуруза сорта MON810 [15]. Этот сорт обладает повышенной устойчивостью к кукурузному мотыльку, что позволяет бороться с потерей урожая вследствие ущерба от повреждения кукурузы, которой питаются личинки мотылька, без использования традиционных пестицидов [1, с. 8].

По данным социально-экономических исследований за 21 год выращивания этой кукурузы на территории Испании и Португалии, за каждый дополнительный евро, потраченный на семя кукурузы сорта MON810, по сравнению с обычным семенем, фермеры получили дополнительный 4,95 евро дополнительного дохода. Эти доходы были получены, в основном, за счет повышения урожайности (+ 11,5\%). Использование инсектицидов сократилось на 678000 кг активного ингредиента (-37\%), что позволило на $21 \%$ уменьшить воздействие на окружающую среду, связанное с использованием гербицидов и инсектицидов на этих культурах [12].

Также в Законе № 45/2007 указывается на необходимость достижения высокого уровня качества окружающей среды в сельской среде, сохранения биоразнообразия, уменьшения загрязнения в сельской местности. Данные вопрось регулирует отдельный нормативный акт - Закон о природном наследии и биоразнообразии (Закон № 42/2007) [19]. Стратегический план по природному наследию и биоразнообразию был утвержден на 2011-2017 годы Королевским декретом №1.274/2011 [22].

В ст. 54 Закона о природном наследии и биоразнообразии устанавливается, что Генеральная государственная администрация будет запрещать ввоз или интродукцию на всей территории страны чужеродных видов или подвидов, если они смогут конкурировать с местными дикими видами, изменять их генетическую чистоту или экологический баланс. Чужеродные виды - это в том числе ГМО. Для этого предусмотрено ведение реестра таких чужеродных видов и подвидов.

В ст. 63 публичные администрации наделяются полномочиями содействовать существованию банков генетического и биологического материала диких видов для сохранения генетического разнообразия.

Таким образом, запрета на выращивание ГМО в Законе о природном наследии и биоразнообразии нет, но устанавливаются общие требования о сохранении биоразнообразия и генетического разнообразия.

В том, что касается сохранения биоразнообразия, аналогичную функцию в российском законодательстве выполняет ст. 50 Федерального закона от 10 января 2002 г. №7-Ф3 «Об охране окружающей среды» [4], за тем исключением, что в Испании выращивание ГМО не запрещено, а рассматривается как один из способов диверсификации экономики сельского хозяйства.

Как и в России, в Испании есть специальное законодательство, регулирующее вопросы использования ГМО, основу которого составляет Закон №9/2003, устанавливающий правовой режим ограниченного использования, добровольного выпуска и коммерциализации генетически модифицированных организмов [18]

В законе установлены общие принципы, существующие на уровне ЕС и международном уровне, направленные на предупреждение негативных последствий от использования ГМО. Это подразумевает:

- принятие мер предосторожности во избежание потенциального неблагоприятного воздействия ГМО на здоровье человека и окружающую среду;

- оценку риска на индивидуальной основе, то есть оценку рисков, связанных с ГМО, для каждого из них в отдельности;

- последовательную оценку риска, предполагающую переход к выпуску ГМО в окружающую среду только тогда, когда оценка предыдущих этапов показывает, что это может произойти без рисков;

- инфрормирование общественности и ее участие в принятии решений, связанных с использованием ГМО.

В Испании существует три самостоятельных режима использования ГМО, им посвящены отдельные главы закона: 
1) использование ГМО в замкнутых системах (гл. I раздела II) - касается только тех ГМО, которые не имеют разрешения на реализацию;

2) добровольное высвобождение ГМО, в том числе преднамеренный выпуск ГМО в окружающую среду (гл. II раздела II);

3) реализация ГМО и продукции, которая их содержит (гл. III раздела II).

В Испании выделяется четыре уровня риска деятельности по использованию ГМО в замкнутых системах: нулевой, или незначительный, низкий, умеренный и высокий. Деятельность, которой присвоен умеренный и высокий уровень риска, требует государственного разрешения

Уровень риска определяется в зависимости от характера деятельности. Важно, что прежний закон 1994 г. [17] предполагал оценку риска в зависимости от свойств ГМО, как это предусмотрено и в российском законодательстве [3]. Оценка данного риска исходя из характера деятельности по использованию ГМО - новелла Закона №9/2003.

Традиционно выделяется четыре уровня такого риска - нулевой, или незначительный, низкий, умеренный и высокий.

Преднамеренный выпуск ГМО в окружающую среду всегда требует предварительного разрешения и оценки рисков.

При этом в соответствии с Директивой 2001/18/ ЕС из сферы действия закона исключены такие специфические виды продукции, как лекарственные вещества и соединения, предназначенные для использования человеком, которые состоят из ГМО или их комбинаций или содержат ГМО. Предполагается, что порядок их применения вне замкнутой системы регулируется нормами специального законодательства. Однако в нем должны содержаться правила, предусмотренные рассматриваемым законом.

Такой подход представляется обоснованным в силу особой специфики лекарственной продукции и распространения на нее строгих норм законодательства о медицинских генотерапевтических препаратах и биомедицинских клеточных продуктах.

Реализация ГМО и содержащей их продукции, как возмездно, так и на безвозмездной основе, также требует получения разрешения. Предусмотренные законом требования основаны на общеевропейском опыте регулирования оборота ГМО и содержащей ГМО продукции. В целом они соответствуют правилам, установленным в российском законодательстве. Именно сегмент, связанный с регулированием выпуска на рынок продукции, содержащей ГМО, и контролем за ее реализацией, наиболее развит в Российской Федерации.

Предполагается, что ГМО, сами по себе являющиеся продуктами или их компонентами, лекарства для человека или ветеринарного применения, которые состоят из ГМО или их комбинаций или содержат такие организмы, регулируются специальным законодательством. Однако обязательной в любом случае является оценка рисков для окружающей среды, эквивалентная предусмотренной рассматриваемым законом

Разрешения на использование ГМО в замкнутых системах, добровольное высвобождение ГМО и реализацию ГМО выдает Межведомственный совет по генетически модифицированным организмам, состоящий из представителей компетентных министерских департаментов.

Это один из двух коллегиальных органов формирование которых предусматривает Закон №9/2003. Вторым является Комиссия по национальной биобезопасности. Оба органа формируются при Министерстве окружающей среды. К сожалению, в России в настоящее время нет какого-либо аналогичного органа, с которым можно было бы сравнить их работу, хотя изначально Федеральный закон от 5 июля 1996 г. №86-Ф3 «О государственном регулировании в области генно-инженерной деятельности» предусматривал формирование и компетенцию Межведомственной комиссии по генно-инженерной деятельности.

Статьи 34 и 35 Закона №9/2003 устанавливают административную ответственность за нарушение требований закона. Представляет интерес классификация нарушений по степени их опасности: перечислены конкретные нарушения, которые следует считать незначительными, серьезными или очень серьезными. Санкции различаются: небольшие и очень большие штрафы (в 1200000 евро), приостановление деятельности, изъятие ГМО и продукции, отзыв разрешения на их использование, запрет их реализации и др.

Определение конкретных правонарушений, за которые наступает ответственность, и их категоризация следует учесть при совершенствовании норм российского законодательства об административной ответственности за неправомерное использование ГМО и продукции, которая из них получена, произведена или их содержит. В нем много пробелов, в частности - не установлена ответственность за непреднамеренный выпуск ГМО в окружающую среду, за преднамеренный выпуск ГМО, не требующих регистрации, с нарушениями требований безопасности, а также за намеренное выращивание ГМО на территории России в иных целях.

В ст. 36 предусмотрен важный механизм - меры предосторожности. Это административно-предупредительные меры, осуществляемые компетентной администрацией, если она установит, что деятельность осуществляется без соответствующего разрешения или может нанести серьезный ущерб здоровью людей или окружающей среде. В этом случае государственные органы могут закрыть объект или его часть, где осуществляется указанная деятельность, а также конфисковать ГМО или продукцию, которая их содержит. В российском законодательстве нет аналогичной меры, и это его явный недостаток. Ее введение необходимо для предотвращения ущерба в случаях выращивания ГМО с риском для человека и окружающей среды, что возможно при непреднамеренном выпуске ГМО в окружающую среду, 
выращивании ГМО в научно-исследовательских экспертных целях с нарушениями установленных требований, а также при намеренном незаконном выращивании ГМО на территории России.

Во исполнение Закона № 9/2003 принят Королевский декрет № 178/2004 [23]. Он детализирует общие правила, предусмотренные законом, в соответствии с Директивой 2001/18/EC и регламентирует ведение единого реестра ГМО получивших разрешения. В таком реестре в обязательном порядке должна отражаться инорормация о месте выращивания ГМО

В целом нормативный акт, приятый во исполнение закона, весыма детально описывает порядок и основания для получения разрешения на деятельность, связанную с использованием ГМО Так, ст. 21 регулирует действия хозяйствующих субъектов в случае аварии, приведшей к высвобождению ГМО. Аналогичные по назначению нормы также необходимы в российской системе безопасности генно-инженерной деятельности, но отсутствуют.

Подводя итог сказанному, следует сделать вывод о высокой проработанности законодательства Испании о выращивании ГМО, имеющего в основе нормы законодательства ЕС.

Рассмотренное законодательство, несмотря на это, также следует оценивать критически. В частности, исследователями отмечается недостаточная проработка в Испании социально-экономических рисков при выращивании ГМ-культур что может негативно влить на пчеловодство в тех районах, где их выращивают [11, р. 546]

Однако для российского законодательства развивающегося фрагментарно и неравномерно, испанский нормотворческий опыт может стать полезен, при условии одновременного развития норм об устойчивом сосуществовании органической, традиционной и биотехнологической продукции.

Как нами отмечалось ранее, одной из основных проблем российского законодательства о генно-инженерной деятельности является недостаточная проработка оценки уровня риска деятельности, связанной с ГМО [7]. На наш взгляд переход к оценке риска в зависимости от характера осуществляемой деятельности, а не ГМО с которыми ведется работа, позволит пересмотреть всю систему оценки риска и станет отправной точкой для модернизации существующего механизма административно-правового регулирования в отношении ГМО. Именно такой подход закрепляет Закон Испании №9/2003, и его стоит воспринять в российском законодательстве, которое при оценке риска генно-инженерной деятельности по-прежнему отсылает к уровням патогенности микроорганизмов.

Также в отсутствие в современном законодательстве России требований к использованию ГМО в замкнутых системах следует внимательно изучить опыт Испании в установлении таких нор- мативных требований на основании ст. 7 Закона №9/2003. Представляет интерес практика выдачи разрешений на осуществление деятельности по использованию в замкнутых системах $Г \mathrm{MO}$, отнесенных к категории умеренного или высокого риска. В России такая деятельность подлежит лицензированию, но фрактически оно не осуществляется. Изучение опыта Испании позволит понять, в каких направлениях можно дальше развивать механизм лицензирования деятельности, связанной с использованием ГМО.

Главной целью административно-правового механизма регулирования применения геномных и постгеномных технологий в растениеводстве является обеспечение безопасности человека и окружающей среды, поэтому представляется необходимым включить в него нормы:

- о необходимых действиях в случае аварии при использовании ГМО в замкнутых системах, хотя бы для наиболее высоких уровней риска;

- о мерах предосторожности при работе с ГМО в случае выявления нарушений или угрозы безопасности человека и окружающей среды.

Также испанский опыт целесообразно использовать для дополнения законодательства об административной ответственности нормами, предусматривающими ответственность за нарушение требований при выпуске ГМО в окружающую среду. Здесь интерес представляют конкретные составы правонарушений, выделенные испанским законодателем, их категоризация по степени серьезности и, соответственно, видам применяемых санкций

Наконец, существенным элементом механизма административно-правового регулирования в России является создание межведомственного органа, обладающего рядом контрольных, координационных и регулятивных полномочий. При разработке нового положения о таком органе и определении его компетенции будет полезен опыт работы действующих в Испании Межведомственного совета по генетически модифицированным организмам и Комиссии по национальной биобезопасности.

В целом, можно говорить, что административно-правовое регулирование применения геномных технологий в сельском хозяйстве в Испании осуществляется системно, позволяя защищать интересы и фермеров, и жителей на безопасную окружающую среду. Отдельные элементы такого регулирования, связанные с оценкой риска использования ГМО, установлением требований безопасности к использованию ГМО в замкнутых системах, применением предупредительных мер и мер административной ответственности, формированием межведомственных органов по вопросам безопасности ГМО, могут быть восприняты российским законодателем в целях развития российского механизма административно-правового регулирования применения геномных технологий в растениеводстве. 


\section{Литература}

1. Кверчи М., Раццара М. Анализ образцов пищевых продуктов на присутствие генетически модифицированных организмов. Сессия 7. Характеристика сои Roundup Ready®, кукурузы MON810 и кукурузы Bt-176. BO3. Европейское региональное бюро. 21 c. URL: http://gmo-crl.jrc.ec.europa.eu/capacitybuilding/manuals/manual\%20RUS/UM\%20Rus-S7. pdf (Дата обращения: 20.06.2019).

2. Комплексная программа развития биотехнологий в Российской Федерации на период до 2020 года: утв. Правительством Россиской Федерации от 24 апреля 2012 г. №1853п-П8 // Правительство России. URL: http://static. government.ru/media/files/41d4e85fob854eb1b02d.pdf (Дата обращения: 20.06.2019).

3. О государственном регулировании в области генно-инженерной деятельности: федер. закон от 5 июля 1996 г. № 86-Ф3: ред. от 3 июля 2016 г. // С3 РФ. 1996. №28. Ст.3348; 2016. №27 (часть II). Ст. 4291

4. Об охране окружающей среды: федер. закон от 10 января 2002 г. №7-ФЗ: в ред. от 29 июля 2018 г. // СЗ РФ. 1999. №14. Ст. 1650; 2018. №31. Ст. 4841.

5. Основы законодательства в области генной инженерии // Германо-российский аграрно-политический диалог URL: https://agrardialog.ru/files/prints/gmo_osnovi_zakonodatelstva_es_germaniya_2016_1.pdf (Дата обращения: 01.06.2019).

6. Петушкова Ю. А. Правовое регулирование в сфере биотехнологии в зарубежных странах // Экологическое право. 2013. №2. C. 20-25.

7. Соколов А. Ю., Богатырева Н. В. Определение уровня риска в области генно-инженерной деятельности // Административное право и процесс. 2018. №8. С. 32-36.

8. Чиркин В. Е. Наднациональное право: основные особенности // Журнал российского права. 2017. №2 (242) C. $18-25$.

9. Энтин Л. М. Право Европейского Союза. Новый этап эволюции: 2009-2017 годы. М.: Аксиом, 2009. 148 с.

10. A decade of EU-funded GMO research (2001-2010) //Directorate-General for Research and Innovation Biotechnologies Agriculture, Food, 2010. 266 p. URL: http://ec.europa.eu/research/biosociety/pdf/a_decade_of_eu-funded_gmo_research.pdf (Accessed: 20.06.2019)

11. Binimelis R., Wickson F. The troubled relationship between GMOs and beekeeping: an exploration of socioeconomic impacts in Spain and Uruguay // Agroecology and Sustainable Food Systems. 2019. 43:5. P. 546-578. DOI: 10.1080/21683565.2018.1514678.

12. Brookes G. Twenty-one years of using insect resistant (GM) maize in Spain and Portugal: farm-level economic and environmental contributions // GM Crops \& Food. 2019. DOI: 10.1080/21645698.2019.1614393.

13. Directive 2001/18/EC of the European Parliament and of the Council of 12 March 2001 on the deliberate release into the environment of genetically modified organisms and repealing Council Directive 90/220/EEC // Official Journal of the European Union, L 06. 17 April 2001. P.1-38.

14. Directive (EU) 2015/412 of the European Parliament and of the Council of 11 March 2015 amending Directive 2001/18/ EC as regards the possibility for the Member States to restrict or prohibit the cultivation of genetically modified organisms (GMOs) in their territory // Official Journal of the European Union, L 68. 13 March 2015. P.1-8.

15. Genetically Modified Organisms MON-Øø81Ø-6// GMO Register. URL: https://webgate.ec.europa.eu/dyna/gm register/gm_register_auth.cfm?pr_id=11 (Accessed: 20.06.2019).

16. Global Status of Commercialized Biotech/GM Crops in 2017: ISAAA Brief No. 53. ISAAA. 2017. 143 p.

17. Ley № 15/1994 - Régimen jurídico de la utilización confinada, liberación voluntaria y comercialización de organismos modificados genéticamente, a fin de prevenir los riesgos para la salud humana y para el medio ambiente // Boletín Oficial del Estado $\mathrm{N}^{\circ} 133,4$ de junio de 1994. P.17781-17788.

18. Ley № 9/2003 - Régimen jurídico de la utilización confinada, liberación voluntaria y comercialización de organismos modificados genéticamente // Boletín Oficial del Estado № 299, 14 de diciembre de 2007. P.51275-51327; No100, 26 de abril de 2003. P.16214-16223.

19. Ley № $42 / 2007$ - Ley del Patrimonio Natural y de la Biodiversidad: modificada el 20 de julio de 2018 // Boletín Oficial del Estado N²99, 14 de diciembre de 2007. P.51275-51327; N¹76, 21 de julio de 2018. P.73196- 73202.

20. Ley № 45/2007, de 13 de diciembre, para el desarrollo sostenible del medio rural // Boletín Oficial del Estado №299. 14 diciembre 2007. P. 51339-51449.

21. Panchin A.Y., Tuzhikov A.I. Published GMO studies find no evidence of harm when corrected for multiple comparisons // Critical Reviews in Biotechnology. 2016. P.213-217. DOI: 10.3109/07388551.2015.1130684.

22. Real Decreto № 1.274/2011 - Plan estratégico del patrimonio natural y de la biodiversidad 2011-2017 // Boletín Oficial del Estado № 236, de 30 de septiembre de 2011. P.103071 - 103280

23. Real Decreto № 178/2004 - Reglamenta la Ley No 9/2003, sobre régimen jurídico de la utilización confinada, liberación voluntaria y comercialización de organismos modificados genéticamente // Boletín Oficial del Estado $N^{\circ} 27$. 31 de enero de 2004. P. $4171-4216$

\section{References}

1. Querci M., Mazzara M. Analiz obraztsov pishchevykh produktov na prisutstvie geneticheski modifitsirovannykh organizmov. Sessiya 7. Kharakteristika soi Roundup ReadyR, kukuruzy MON810 i kukuruzy Bt-176 (The Analysis of Food Samples for the Presence of Genetically Modified Organisms. Session 7. Characteristics of Roundup Ready ${ }^{\circledR}$ Soybean, MON810 Maize, and Bt-176 Maize). VOZ. Evropeiskoe regional'noe byuro. 21 p. URL: http://gmo-crl.jrc.ec.europa.eu/ capacitybuilding/manuals/manual\%20RUS/UM\%20Rus-S7.pdf (Accessed: 20.06.2019) (In Russian)

2. Kompleksnaya programma razvitiya biotekhnologii v Rossiiskoi Federatsii na period do 2020 goda (Comprehensive program for the development of biotechnology in the Russian Federation for the period up to 2020): utv. Pravitel'stvom Ros. Federatsii ot 24 aprelya 2012 g. № 1853p-P8 // Pravitel'stvo Rossii. URL: http://static.government.ru/media/ files/41 d4e85f0b854eb1b02d.pdf (Accessed: 20.06.2019). (In Russian). 
3. O gosudarstvennom regulirovanii v oblasti genno-inzhenernoi deyatel'nosti: feder. zakon ot 5 iyulya $1996 \mathrm{~g}$. № $86-\mathrm{FZ}$ : red. ot 3 iyulya 2016 g. (On State Regulation in the Field of Genetic Engineering: Federal Law No. 86-Ф3) // SZ RF. 1996. No. 28. Art. 3348; 2016. No. 27 (Part II). Art. 4291. (In Russian).

4. Ob okhrane okruzhayushchei sredy: feder. zakon ot 10 yanvarya $2002 \mathrm{~g}$. № 7-FZ: v red. of 29 iyulya $2018 \mathrm{~g}$. (On the environment: Federal Law No. 7-Ф3) // SZ RF. 1999. No. 14. Art. 1650; 2018. No. 31. Art. 4841. (In Russian).

5. Osnovy zakonodatel'stva v oblasti gennoi inzhenerii (Fundamentals of legislation in the field of genetic engineering) /I Germano-rossiiskii agrarno-politicheskii dialog: URL: https://agrardialog.ru/files/prints/gmo_osnovi_zakonodatelstva_es_ germaniya 2016 1.pdf (Accessed: 01.06.2019). (In Russian).

6. Petushkova Yu. A. Pravovoe regulirovanie v sfere biotekhnologii v zarubezhnykh stranakh (Legal regulation in the field of biotechnology in foreign countries) // Ekologicheskoe pravo. 2013. No. 2. 20-25. (In Russian).

7. Sokolov A. Yu., Bogatyreva N. V. Opredelenie urovnya riska $v$ oblasti genno-inzhenernoi deyatel'nosti (Risk level determination in the field of genetic engineering activities) // Administrativnoe pravo i protsess. 2018. No. 8. P. 32-36. (In Russian).

8. Chirkin V. E. Nadnatsional'noe pravo: osnovnye osobennosti (Supranational law: main features) // Zhurnal rossiiskogo prava. 2017. No. 2 (242). P. 18-25. (In Russian).

9. Entin L. M. Pravo Evropeiskogo Soyuza. Novyi etap evolyutsii: 2009-2017 gody (European Union law. New stage of evolution: 2009-2017). Moscow: Aksioma, 2009. 148 p. (In Russian).

10. A decade of EU-funded GMO research (2001-2010) // Directorate-General for Research and Innovation Biotechnologies, Agriculture, Food, 2010.266 p. URL: http://ec.europa.eu/research/biosociety/pdf/a_decade_of_eu-funded_gmo_research.pdf (дата обращения: 20.06.2019); National Academies of Sciences, Engineering, and Medicine. 2016. Genetically Engineered Crops: Experiences and Prospects. Washington, DC: The National Academies Press. 606 p. DOI: 10.17226/23395.

11. Binimelis R., Wickson F. The troubled relationship between GMOs and beekeeping: an exploration of socioeconomic impacts in Spain and Uruguay // Agroecology and Sustainable Food Systems. 2019. 43:5. P. 546-578. DOI: 10.1080/21683565.2018.1514678

12. Brookes G. Twenty-one years of using insect resistant (GM) maize in Spain and Portugal: farm-level economic and environmental contributions // GM Crops \& Food. 2019. DOI: 10.1080/21645698.2019.1614393.

13. Directive 2001/18/EC of the European Parliament and of the Council of 12 March 2001 on the deliberate release into the environment of genetically modified organisms and repealing Council Directive 90/220/EEC // Official Journal of the European Union, L 06. 17 April 2001. P. 1-38.

14. Directive (EU) 2015/412 of the European Parliament and of the Council of 11 March 2015 amending Directive 2001/18/ $\mathrm{EC}$ as regards the possibility for the Member States to restrict or prohibit the cultivation of genetically modified organisms (GMOs) in their territory // Official Journal of the European Union, L 68. 13 March 2015. P. 1-8.

15. Genetically Modified Organisms MON-ØØ81Ø-6 // GMO Register. URL: https://webgate.ec.europa.eu/dyna/gm_ register/gm_register_auth.cfm?pr_id=11 (Accessed: 20.06.2019).

16. Global Status of Commercialized Biotech/GM Crops in 2017: ISAAA Brief No. 53. ISAAA. 2017. P. 94. 143 p.

17. Ley № 15/1994 - Régimen jurídico de la utilización confinada, liberación voluntaria y comercialización de organismos modificados genéticamente, a fin de prevenir los riesgos para la salud humana y para el medio ambiente // Boletín Oficial del Estado N0133, 4 de junio de 1994. P. 17781-17788.

18. Ley № 9/2003 - Régimen jurídico de la utilización confinada, liberación voluntaria y comercialización de organismos modificados genéticamente // Boletín Oficial del Estado №299, 14 de diciembre de 2007. P.51275-51327; №100. 26 de abril de 2003. P. 16214-16223.

19. Ley № 42/2007 - Ley del Patrimonio Natural y de la Biodiversidad: modificada el 20 de julio de 2018 // Boletín Oficial del Estado No299, 14 de diciembre de 2007. P.51275-51327; N0176. 21 de julio de 2018. P. 73196-73202.

20. Ley № 45/2007, de 13 de diciembre, para el desarrollo sostenible del medio rural // Boletín Oficial del Estado №299. 14 diciembre 2007. P. 51339-51449.

21. Panchin A. Y., Tuzhikov A. I. Published GMO studies find no evidence of harm when corrected for multiple comparisons // Critical Reviews in Biotechnology. 2016. P. 213-217. DOI: 10.3109/07388551.2015.1130684.

22. Real Decreto № 1.274/2011 - Plan estratégico del patrimonio natural y de la biodiversidad 2011-2017 // Boletín Oficial del Estado. №236. de 30 de septiembre de 2011. P. 103071-103280.

23. Real Decreto № 178/2004 - Reglamenta la Ley № 9/2003, sobre régimen jurídico de la utilización confinada, liberaciỏn voluntaria y comercialización de organismos modificados genéticamente // Boletín Oficial del Estado. №27. 31 de enero de 2004. P. 4171-4216.

\section{Сведения об авторах}

Соколов Александр Юрьевич - доктор юридических наук, заведующий кафедрой административного и муниципального права Саратовской государственной юридической академии (Саратов) / aysockolov@mail.ru

Богатырева Наталия Владимировна - ассистент кафедры административного и муниципального права Саратовской государственной юридической академии (Саратов) / nvbogatyreva@gmail.com 


\section{Information about the authors}

Sokolov Alexandr - Doctor of Law, Professor, Chair of Administrative and Municipal Law, Saratov State Law Academy (Saratov) / aysockolov@mail.ru

Bogatyreva Nataliya - Assistant, Chair of Administrative and Municipal Law, Saratov State Law Academy (Saratov)/nvbogatyreva@gmail.com 